\title{
On Some New Contra Continuous and Contra Open Mappings in Intuitionistic Fuzzy Topological Spaces
}

\author{
M. Thirumalaiswamy \\ Department of Mathematics, \\ NGM College, Pollachi-642001, \\ Tamil Nadu, India.
}

\author{
K. M. Arifmohammed \\ Department of Mathematics, \\ NGM College, Pollachi-642001, \\ Tamil Nadu, India.
}

\begin{abstract}
In this paper we introduce intuitionistic fuzzy contrasemipre generalized continuous mappings, intuitionistic fuzzy almost contra semipregeneralized continuous mappings and intuitionistic fuzzy contra semipre generalized open mappings. We study some of their properties.
\end{abstract}

Keywords: Intuitionistic fuzzy point, intuitionistic fuzzy topology, intuitionistic fuzzy contra semipre generalized continuous mappings, intuitionistic fuzzy almost contra semipre generalized continuous mappings and intuitionistic fuzzy contra semipre generalized open mappings.

AMS Subject Classification (2000): 54A40, $03 \mathrm{~F} 55$.

\section{INTRODUCTION}

In 1965, Zadeh [13] introduced fuzzy sets and in 1968, Chang [2] introduced fuzzy topology. After the introduction of fuzzy set and fuzzy topology, several authors were conducted on the generalization of this notion. The notion of intuitionistic fuzzy sets was introduced by Atanassov [1] as a generalization of fuzzy sets. In 1997, Coker [3] introduced the concept of intuitionistic fuzzy topological spaces. In 2005, Young Bae Jun and SeokZun Song [12] introduced Intuitionistic fuzzy semipre continuous mappings in intuitionistic fuzzy topological spaces. In this paper we introduce intuitionistic fuzzy contra semipre generalized continuous mappings, intuitionistic fuzzy almost contra semipre generalized continuous mappings and intuitionistic fuzzy contra semipre generalized open mappings. We investigate some of their properties.

\section{PRELIMINARIES}

Definition 2.1: [1] Let $X$ be a non-empty fixed set. An intuitionistic fuzzy set (IFS in short) $\mathrm{A}$ in $\mathrm{X}$ is an object having the form $\mathrm{A}=\left\{\left\langle\mathrm{x}, \mu_{\mathrm{A}}(\mathrm{x}), v_{\mathrm{A}}(\mathrm{x})\right\rangle / \mathrm{x} \in \mathrm{X}\right\}$ where the functions $\mu_{\mathrm{A}}: \mathrm{X} \rightarrow[0,1]$ and $v_{\mathrm{A}}: \mathrm{X} \rightarrow[0,1]$ denote the degree of membership (namely $\mu_{\mathrm{A}}(\mathrm{x})$ ) and the degree of nonmembership (namely $v_{\mathrm{A}}(\mathrm{x})$ ) of each element $\mathrm{x} \in \mathrm{X}$ to the set A, respectively, and $0 \leq \mu_{A}(x)+v_{A}(x) \leq 1$ for each $x \in X$. Denote by IFS(X), the set of all intuitionistic fuzzy sets in $X$.

Definition 2.2: [1] Let $A$ and $B$ be IFSs of the form $A=\{\langle x$, $\left.\left.\mu_{\mathrm{A}}(\mathrm{x}), v_{\mathrm{A}}(\mathrm{x})\right\rangle / \mathrm{x} \in \mathrm{X}\right\}$ and $\mathrm{B}=\left\{\left\langle\mathrm{x}, \mu_{\mathrm{B}}(\mathrm{x}), v_{\mathrm{B}}(\mathrm{x})\right\rangle / \mathrm{x} \in \mathrm{X}\right\}$. Then 1. $\quad \mathrm{A} \subseteq \mathrm{B}$ if and only if $\mu_{\mathrm{A}}(\mathrm{x}) \leq \mu_{\mathrm{B}}(\mathrm{x})$ and $v_{\mathrm{A}}(\mathrm{x}) \geq v_{\mathrm{B}}(\mathrm{x})$ for all $\mathrm{x} \in \mathrm{X}$

2. $\mathrm{A}=\mathrm{B}$ if and only if $\mathrm{A} \subseteq \mathrm{B}$ and $\mathrm{B} \subseteq \mathrm{A}$

3. $\quad \mathrm{A}^{\mathrm{c}}=\left\{\left\langle\mathrm{x}, v_{\mathrm{A}}(\mathrm{x}), \mu_{\mathrm{A}}(\mathrm{x})\right\rangle / \mathrm{x} \in \mathrm{X}\right\}$

4. $\quad \mathrm{A} \cap \mathrm{B}=\left\{\left\langle\mathrm{x}, \mu_{\mathrm{A}}(\mathrm{x}) \wedge \mu_{\mathrm{B}}(\mathrm{x}), v_{\mathrm{A}}(\mathrm{x}) \vee v_{\mathrm{B}}(\mathrm{x})\right\rangle / \mathrm{x} \in \mathrm{X}\right\}$ 5. $\quad \mathrm{A} \cup \mathrm{B}=\left\{\left\langle\mathrm{x}, \mu_{\mathrm{A}}(\mathrm{x}) \vee \mu_{\mathrm{B}}(\mathrm{x}), v_{\mathrm{A}}(\mathrm{x}) \wedge v_{\mathrm{B}}(\mathrm{x})\right\rangle / \mathrm{x} \in \mathrm{X}\right\}$ For the sake of simplicity, we shall use the notation $A=\langle x$, $\left.\mu_{\mathrm{A}}, v_{\mathrm{A}}\right\rangle$ instead of $\mathrm{A}=\left\{\left\langle\mathrm{x}, \mu_{\mathrm{A}}(\mathrm{x}), v_{\mathrm{A}}(\mathrm{x})\right\rangle / \mathrm{x} \in \mathrm{X}\right\}$. The intuitionistic fuzzy sets $0_{\sim}=\{\langle\mathrm{x}, 0,1\rangle / \mathrm{x} \in \mathrm{X}\}$ and $1_{\sim}=\{\langle\mathrm{x}, 1$, $0\rangle / x \in X\}$ are respectively the empty set and the whole set of $\mathrm{X}$.
Definition 2.3: [3] An intuitionistic fuzzy topology (IFT in short) on $\mathrm{X}$ is a family $\tau$ of IFSs in X satisfying the following axioms:

1. $0_{\sim}, 1_{\sim} \in \tau$

2. $\mathrm{G}_{1} \cap \mathrm{G}_{2} \in \tau$, for any $\mathrm{G}_{1}, \mathrm{G}_{2} \in \tau$

3. $\quad \mathrm{GG}_{\mathrm{i}} \in \tau$ for any family $\left\{\mathrm{G}_{\mathrm{i}} / \mathrm{i} \in \mathrm{J}\right\} \subseteq \tau$

In this case the pair $(X, \tau)$ is called an intuitionistic fuzzy topological space(IFTS in short) and any IFS in $\tau$ is known as an intuitionistic fuzzy open set(IFOS in short)in $X$. The complement $\mathrm{A}^{\mathrm{c}}$ of an IFOS $\mathrm{A}$ in an IFTS $(\mathrm{X}, \tau)$ is called an intuitionistic fuzzy closed set (IFCS in short) in X.

Definition 2.4: [3] Let $(X, \tau)$ be an IFTS and $A=\left\langle x, \mu_{A}, v_{A}\right\rangle$ be an IFS in X. Then

1. $\quad \operatorname{int}(\mathrm{A})=\mathrm{U}\{\mathrm{G} / \mathrm{G}$ is an IFOS in $\mathrm{X}$ and $\mathrm{G} \subseteq \mathrm{A}\}$

2. $\quad \operatorname{cl}(\mathrm{A})=\cap\{\mathrm{K} / \mathrm{K}$ is an IFCS in $\mathrm{X}$ and $\mathrm{A} \subseteq \mathrm{K}\}$

3. $\quad \operatorname{cl}\left(\mathrm{A}^{\mathrm{c}}\right)=(\operatorname{int}(\mathrm{A}))^{\mathrm{c}}$

4. $\quad \operatorname{int}\left(\mathrm{A}^{\mathrm{c}}\right)=(\mathrm{cl}(\mathrm{A}))^{\mathrm{c}}$

Definition 2.5: [5] An IFS A of an IFTS $(X, \tau)$ is an

1. intuitionistic fuzzy preclosed set (IFPCS in short) if $\operatorname{cl}(\operatorname{int}(\mathrm{A})) \subseteq \mathrm{A}$

2. intuitionistic fuzzy preopen set (IFPOS in short) if A $\subseteq \operatorname{int}(\mathrm{cl}(\mathrm{A}))$

Note that every IFOS in $(X, \tau)$ is an IFPOS in $\mathrm{X}$.

Definition 2.6: [5] An IFS A of an IFTS $(X, \tau)$ is an

1. intuitionistic fuzzy $\alpha$-closed set (IF $\alpha \mathrm{CS}$ in short) if $\operatorname{cl}(\operatorname{int}(\operatorname{cl}(\mathrm{A}))) \subseteq \mathrm{A}$

2. intuitionistic fuzzy $\alpha$-open set (IF $\alpha \mathrm{OS}$ in short) if A $\subseteq \operatorname{int}(\operatorname{cl}(\operatorname{int}(\mathrm{A})))$

3. intuitionistic fuzzy regular closed set (IFRCS in short) if $\mathrm{A}=\operatorname{cl}(\operatorname{int}(\mathrm{A}))$

4. intuitionistic fuzzy regular open set (IFROS in short) if $\mathrm{A}=\operatorname{int}(\mathrm{cl}(\mathrm{A}))$

Definition 2.7: [12] An IFS A of an IFTS (X, $\tau$ ) is an 1. intuitionistic fuzzy semipre closed set (IFSPCS in short) if there exists an IFPCS B such that int(B) $\subseteq \mathrm{A} \subseteq \mathrm{B}$

2. intuitionistic fuzzy semipre open set (IFSPOS in short) if there exists an IFPOS B such that $\mathrm{B} \subseteq \mathrm{A} \subseteq \mathrm{cl}(\mathrm{B})$

Definition 2.8:[9] An IFS A is an IFTS $(X, \tau)$ is said to be an intuitionistic fuzzy semipregeneralized closed set (IFSPGCS 
International Journal of Computer Applications Technology and Research

Volume 2- Issue 2, 109 - 116, 2013, ISSN: 2319-8656

in short) if $\operatorname{spcl}(\mathrm{A}) \subseteq \mathrm{U}$ whenever $\mathrm{A} \subseteq \mathrm{U}$ and $\mathrm{U}$ is an IFSOS in $(X, \tau)$.

Every IFCS, IFaCS, IFRCS, IFPCS and IFSPCS is an IFSPGCS but the converses are not true in general.

Definition 2.9:[7] The complement $A^{c}$ of an IFSPGCS A in an $\operatorname{IFTS}(X, \tau)$ is called an intuitionistic fuzzy semipre generalized open set (IFSPGOS in short) in X.

The family of all IFSPGOSs of an IFTS $(X, \tau)$ is denoted by IFSPGO $(\mathrm{X})$. Every IFOS, IF $\alpha O S$, IFROS, IFPOS and IFSPOS is an IFSPGOS but the converses are not true in general.

Definition 2.10: [6] Let $\alpha, \beta \in[0,1]$ and $\alpha+\beta \leq 1$. An intuitionistic fuzzy point (IFP for short) $\mathrm{p}_{(\alpha, \beta)}$ of $\mathrm{X}$ is an IFS of $\mathrm{X}$ defined by

$\mathrm{p}_{(\alpha, \beta)}(y)= \begin{cases}(\alpha, \beta) & \text { if } y=p \\ (0,1) & \text { if } y \neq p\end{cases}$

Definition 2.11: [5] Let $A$ be an IFS in $\operatorname{an} \operatorname{IFTS}(X, \tau)$. Then 1. $\quad \operatorname{spint}(\mathrm{A})=\mathrm{U}\{\mathrm{G} / \mathrm{G}$ is an IFSPOS in $\mathrm{X}$ and $\mathrm{G} \subseteq \mathrm{A}\}$ 2. $\quad \operatorname{spcl}(\mathrm{A})=\bigcap\{\mathrm{K} / \mathrm{K}$ is an IFSPCS in $\mathrm{X}$ and $\mathrm{A} \subseteq \mathrm{K}\}$

Note that for any IFS $A$ in $(X, \tau)$, we have $\operatorname{spcl}\left(A^{c}\right)=$ $(\operatorname{spint}(\mathrm{A}))^{\mathrm{c}}$ and $\operatorname{spint}\left(\mathrm{A}^{\mathrm{c}}\right)=(\operatorname{spcl}(\mathrm{A}))^{\mathrm{c}}$.

Definition 2.12: [11] Let $A$ be an IFS in an IFTS $(X, \tau)$. Then semipre generalized interior of A (spgint(A) in short) and semipre generalized closure of $\mathrm{A}(\operatorname{spgcl}(\mathrm{A})$ for short) are defined by

1. $\operatorname{spgint}(A)=U\{G / G$ is an IFSPGOS in $X$ and $G \subseteq$

A\}

2. $\operatorname{spgcl}(\mathrm{A})=\cap\{\mathrm{K} / \mathrm{K}$ is an IFSPGCS in $\mathrm{X}$ and $\mathrm{A} \subseteq$

$\mathrm{K}$ \}

Note that for any IFS $\mathrm{A}$ in $(\mathrm{X}, \tau)$, we have $\operatorname{spgcl}\left(\mathrm{A}^{\mathrm{c}}\right)=$ $(\operatorname{spgint}(\mathrm{A}))^{\mathrm{c}}$ and $\operatorname{spgint}\left(\mathrm{A}^{\mathrm{c}}\right)=(\operatorname{spgcl}(\mathrm{A}))^{\mathrm{c}}$.

Definition 2.13: [7] If every IFSPGCS in $(X, \tau)$ is an IFSPCS in $(X, \tau)$, then the space can be called as an intuitionistic fuzzy semipre $\mathrm{T}_{1 / 2}\left(\right.$ IFSPT $_{1 / 2}$ for short) space.

Definition 2.14:[10] A mapping $\mathrm{f}:(\mathrm{X}, \tau) \rightarrow(\mathrm{Y}, \sigma)$ is called an intuitionistic fuzzy semipre generalized continuous (IFSPG continuous for short) mappings if $\mathrm{f}^{-1}(\mathrm{~V})$ is an IFSPGCS in (X, $\tau)$ for every IFCS $V$ of $(Y, \sigma)$.

Definition 2.15: [6] A mapppingf : $(X, \tau) \rightarrow(Y, \sigma)$ is called an intuitionistic fuzzy closed mapping (IFCM for short) if $\mathrm{f}(\mathrm{A})$ is an IFCS in Y for each IFCS A in X.

Definition 2.16: [8] A mapping $f:(X, \tau) \rightarrow(Y, \sigma)$ is called an intuitionistic fuzzy semipre generalized closed mapping (IFSPGCM in short) if $\mathrm{f}(\mathrm{A})$ is an IFSPGCS in $\mathrm{Y}$ for each IFCS A in X.

Definition 2.17: [8] A mapping $\mathrm{f}:(\mathrm{X}, \tau) \rightarrow(\mathrm{Y}, \sigma)$ is said to be an intuitionistic fuzzy M-semipre generalized closed mapping (IFMSPGCM in short) if $\mathrm{f}(\mathrm{A})$ is an IFSPGCS in $\mathrm{Y}$ for every IFSPGCS A in X.

Definition 2.18:[10] A mapping $\mathrm{f}:(\mathrm{X}, \tau) \rightarrow(\mathrm{Y}, \sigma)$ be an intuitionistic fuzzy semipre generalized irresolute (IFSPG irresolute) mapping if $\mathrm{f}^{-1}(\mathrm{~V})$ is an IFSPGCS in $(\mathrm{X}, \tau)$ for every IFSPGCS V of $(\mathrm{Y}, \sigma)$.

Definition 2.19: [5]Two IFSs $A$ and $B$ are said to be qcoincident ( $\mathrm{A}_{\mathrm{q}} \mathrm{B}$ in short) if and only if there exists and element $\mathrm{x} \in \mathrm{X}$ such that $\mu_{\mathrm{A}}(\mathrm{x})>v_{\mathrm{B}}(\mathrm{x})$ or $v_{\mathrm{A}}(\mathrm{x})<\mu_{\mathrm{B}}(\mathrm{x})$.
Definition 2.19:[4] A mapping $\mathrm{f}:(\mathrm{X}, \tau) \rightarrow(\mathrm{Y}, \sigma)$ is called an 1. intuitionistic fuzzy contra continuous if $\mathrm{f}^{-1}(\mathrm{~B})$ is an IFCS in $\mathrm{X}$ for everyIFOS B in $\mathrm{Y}$

2. intuitionistic fuzzy contra $\alpha$ continuous if $\mathrm{f}^{-1}(\mathrm{~B})$ is an $\mathrm{IF} \alpha \mathrm{CS}$ in $\mathrm{X}$ for everyIFOS B in Y

3. intuitionistic fuzzy contra pre continuous if $\mathrm{f}^{-1}(\mathrm{~B})$ is an IFPCS in $\mathrm{X}$ forevery IFOS B in Y

\section{INTUITIONISTIC FUZZY CONTRA SEMIPRE GENERALIZED CONTINUOUS MAPPINGS}

In this section we have introduced intuitionistic fuzzy contra semipre generalized continuous mappings. We investigated some of its properties.

Definition 3.1: A mapping $\mathrm{f}:(\mathrm{X}, \tau) \rightarrow(\mathrm{Y}, \sigma)$ is said to be an intuitionistic fuzzy contra semipre generalized continuous mapping (IFCSPG continuous mapping in short) if $\mathrm{f}^{-1}(\mathrm{~A})$ is an IFSPGCS in $\mathrm{X}$ for every IFOS A in Y.

Example 3.2: Let $\mathrm{X}=\{\mathrm{a}, \mathrm{b}\}, \mathrm{Y}=\{\mathrm{u}, \mathrm{v}\}$ and $\mathrm{G}_{1}=\langle\mathrm{x},(0.5$, $0.4),(0.5,0.6)\rangle, \mathrm{G}_{2}=\langle\mathrm{y},(0.4,0.2),(0.6,0.7)\rangle$. Then $\tau=\{0$, $\left.\mathrm{G}_{1}, 1_{\sim}\right\}$ and $\sigma=\left\{0_{\sim}, \mathrm{G}_{2}, 1_{\sim}\right\}$ are IFTs on $\mathrm{X}$ and $\mathrm{Y}$ respectively. Define a mapping $\mathrm{f}:(\mathrm{X}, \tau) \rightarrow(\mathrm{Y}, \sigma)$ by $\mathrm{f}(\mathrm{a})=\mathrm{u}$ and $\mathrm{f}(\mathrm{b})=\mathrm{v}$. Then $\mathrm{f}$ is an IFCSPG continuous mapping.

Theorem 3.3: Every IFC continuous mapping is an IFCSPG continuous mapping but not conversely.

Proof: Let $A \subseteq Y$ be an IFOS. Then $\mathrm{f}^{-1}(\mathrm{~A})$ is an IFCS in $\mathrm{Y}$, by hypothesis. Hencef ${ }^{-1}(\mathrm{~A})$ is an IFSPGCS in X. Therefore $\mathrm{f}$ is an IFCSPG continuous mapping.

Example 3.4: Let $\mathrm{X}=\{\mathrm{a}, \mathrm{b}\}, \mathrm{Y}=\{\mathrm{u}, \mathrm{v}\}$ and $\mathrm{G}_{1}=\langle\mathrm{x},(0.5$, $0.4),(0.5,0.6)\rangle, \mathrm{G}_{2}=\langle\mathrm{y},(0.4,0.2),(0.6,0.7)\rangle$. Then $\tau=\{0 \sim$, $\left.\mathrm{G}_{1,1},\right\}$ and $\sigma=\left\{0 \sim \mathrm{G}_{2}, 1 \sim\right\}$ are IFTs on $\mathrm{X}$ and $\mathrm{Y}$ respectively. Define a mapping $\mathrm{f}:(\mathrm{X}, \tau) \rightarrow(\mathrm{Y}, \sigma)$ by $\mathrm{f}(\mathrm{a})=\mathrm{u}$ and $\mathrm{f}(\mathrm{b})=\mathrm{v}$. Then $\mathrm{f}$ is an IFCSPG continuous mapping but not an IFC continuous mapping.

Theorem 3.5: Every IFC $\alpha$ continuous mapping is an IFCSPG continuous mapping but not conversely.

Proof: Let $A \subseteq Y$ be an IFOS. Then $\mathrm{f}^{-1}(\mathrm{~A})$ is an IF $\alpha C S$ in $\mathrm{X}$, by hypothesis. Hence $f^{-1}(A)$ is an IFGSPCS in X. Therefore $f$ is an IFCSPG continuous mapping.

Example 3.6: Let $\mathrm{X}=\{\mathrm{a}, \mathrm{b}\}, \mathrm{Y}=\{\mathrm{u}, \mathrm{v}\}$ and $\mathrm{G}_{1}=\langle\mathrm{x},(0.5$, $0.4),(0.5,0.6)\rangle, \mathrm{G}_{2}=\langle\mathrm{y},(0.4,0.2),(0.6,0.7)\rangle$. Then $\tau=\{0$, $\left.\mathrm{G}_{1,}, 1_{\sim}\right\}$ and $\sigma=\left\{0_{\sim}, \mathrm{G}_{2}, 1_{\sim}\right\}$ are IFTs on $\mathrm{X}$ and $\mathrm{Y}$ respectively. Define a mapping $\mathrm{f}:(\mathrm{X}, \tau) \rightarrow(\mathrm{Y}, \sigma)$ by $\mathrm{f}(\mathrm{a})=\mathrm{u}$ and $\mathrm{f}(\mathrm{b})=\mathrm{v}$. Then $\mathrm{f}$ is an IFCSPG continuous mapping but not an IFC $\alpha$ continuous mapping.

Theorem 3.7: Every IFCP continuous mapping is an IFCSPG continuous mapping but not conversely.

Proof: Let $A \subseteq Y$ be an IFOS. Then $\mathrm{f}^{-1}(\mathrm{~A})$ is an IFPCS in $\mathrm{X}$, by hypothesis. Hencef ${ }^{-1}(A)$ is an IFSPGCS in X. Therefore $f$ is an IFCSPG continuous mapping.

Example 3.8: Let $\mathrm{X}=\{\mathrm{a}, \mathrm{b}\}, \mathrm{Y}=\{\mathrm{u}, \mathrm{v}\}$ and $\mathrm{G}_{1}=\langle\mathrm{x},(0.5$, $0.6),(0.5,0.4)\rangle, \mathrm{G}_{2}=\langle\mathrm{x},(0.2,0.1),(0.8,0.9)\rangle$ and $\mathrm{G}_{3}=\langle\mathrm{y}$, $(0.2,0.3),(0.8,0.7)\rangle$. Then $\tau=\left\{0_{\sim}, \mathrm{G}_{1}, \mathrm{G}_{2}, 1_{\sim}\right\}$ and $\sigma=\left\{0_{\sim}\right.$, $\left.\mathrm{G}_{3}, 1_{\sim}\right\}$ are IFTs on $\mathrm{X}$ and $\mathrm{Y}$ respectively. Define a mappingf : $(\mathrm{X}, \tau) \rightarrow(\mathrm{Y}, \sigma)$ by $\mathrm{f}(\mathrm{a})=\mathrm{u}$ and $\mathrm{f}(\mathrm{b})=\mathrm{v}$. Then $\mathrm{f}$ is an IFCSPG continuous mapping but not an IFCP continuous mapping. 
International Journal of Computer Applications Technology and Research

Volume 2- Issue 2, 109 - 116, 2013, ISSN: 2319-8656

Theorem 3.9: Let $\mathrm{f}:(\mathrm{X}, \tau) \rightarrow(\mathrm{Y}, \sigma)$ be a mapping. Then the following statements are equivalent:

(i) $\quad \mathrm{f}$ is an IFCSPG continuous mapping

(ii) $\quad \mathrm{f}^{-1}(\mathrm{~A})$ is an IFSPGOS in $\mathrm{X}$ for every IFCS $\mathrm{A}$ in $\mathrm{Y}$

Proof: (i) $\Rightarrow$ (ii) Let $A$ be an IFCS in $Y$. Then $A^{c}$ is an IFOS in $Y$. By hypothesis, $\mathrm{f}^{-1}\left(\mathrm{~A}^{\mathrm{c}}\right)$ is an IFSPGCS in X. That is $\mathrm{f}^{-}$ ${ }^{1}(\mathrm{~A})^{\mathrm{c}}$ is an IFGSPCS in $\mathrm{X}$. Hence $\mathrm{f}^{-1}(\mathrm{~A})$ is an IFSPGOS in $\mathrm{X}$. (ii) $\Rightarrow$ (i) Let $A$ be an IFOS in Y. Then $A^{c}$ is an IFCS in Y. By hypothesis, $\mathrm{f}^{-1}\left(\mathrm{~A}^{\mathrm{c}}\right)$ is an IFSPGOS in $\mathrm{X}$. Hence $\mathrm{f}^{-1}(\mathrm{~A})$ is an IFSPGCS in $\mathrm{X}$. Thus $\mathrm{f}$ is an IFCSPG continuous mapping.

Theorem 3.10: Let $\mathrm{f}:(\mathrm{X}, \tau) \rightarrow(\mathrm{Y}, \sigma)$ be a bijective mapping. Suppose that one of the following properties hold: (i) $\quad \mathrm{f}^{-1}(\mathrm{cl}(\mathrm{B})) \subseteq \operatorname{int}\left(\operatorname{spcl}\left(\mathrm{f}^{-1}(\mathrm{~B})\right)\right)$ for each IFS B in $\mathrm{Y}$ (ii) $\quad \operatorname{cl}\left(\operatorname{spint}\left(\mathrm{f}^{-1}(\mathrm{~B})\right)\right) \subseteq \mathrm{f}^{-1}(\operatorname{int}(\mathrm{B}))$ for each IFS B in $\mathrm{Y}$ (iii) $\quad \mathrm{f}(\mathrm{cl}(\operatorname{spint}(\mathrm{A}))) \subseteq \operatorname{int}(\mathrm{f}(\mathrm{A}))$ for each IFS $\mathrm{A}$ in $\mathrm{X}$ (iv) $\quad \mathrm{f}(\mathrm{cl}(\mathrm{A})) \subseteq \operatorname{int}(\mathrm{f}(\mathrm{A}))$ for each IFSPOS $\mathrm{A}$ in $\mathrm{X}$ Then $\mathrm{f}$ is an IFCSPG continuous mapping.

Proof: (i) $\Rightarrow$ (ii) is obvious by taking complement in (i). (ii) $\Rightarrow$ (iii) Let $A \subseteq X$. Put $B=f(A)$ in $Y$. This implies $A=f^{-}$ ${ }^{1}(\mathrm{f}(\mathrm{A}))=\mathrm{f}^{-1}(\mathrm{~B})$ in $\mathrm{X}$. Now $\mathrm{cl}(\operatorname{spint}(\mathrm{A}))=\operatorname{cl}\left(\operatorname{spint}\left(\mathrm{f}^{-1}(\mathrm{~B})\right)\right) \subseteq \mathrm{f}^{-}$ ${ }^{1}(\operatorname{int}(B))$ by hypothesis. Therefore $\mathrm{f}(\mathrm{cl}(\operatorname{spint}(\mathrm{A}))) \subseteq \mathrm{f}(\mathrm{f}$ $\left.{ }^{1}(\operatorname{int}(\mathrm{B}))\right)=\operatorname{int}(\mathrm{B})=\operatorname{int}(\mathrm{f}(\mathrm{A}))$.

(iii) $\Rightarrow$ (iv) Let $A \subseteq X$ be an IFSPOS. Then $\operatorname{spint}(A)=A$. By hypothesis, $\mathrm{f}(\mathrm{cl}(\operatorname{spint}(\mathrm{A}))) \subseteq \operatorname{int}(\mathrm{f}(\mathrm{A}))$. Therefore $\mathrm{f}(\mathrm{cl}(\mathrm{A}))=$ $\mathrm{f}(\operatorname{cl}(\operatorname{spint}(\mathrm{A}))) \subseteq \operatorname{int}(\mathrm{f}(\mathrm{A}))$.

Suppose (iv) holds: Let $\mathrm{A}$ be an IFOS in $\mathrm{Y}$. Then $\mathrm{f}^{-1}(\mathrm{~A})$ is an IFS in $X$ andspint $\left(\mathrm{f}^{-1}(\mathrm{~A})\right)$ is an IFSPOS in $\mathrm{X}$. Hence by hypothesis, $\mathrm{f}\left(\operatorname{cl}\left(\operatorname{spint}\left(\mathrm{f}^{-1}(\mathrm{~A})\right)\right)\right) \subseteq \operatorname{int}\left(\mathrm{f}\left(\operatorname{spint}\left(\mathrm{f}^{-1}(\mathrm{~A})\right)\right)\right) \subseteq \operatorname{int}\left(\mathrm{f}\left(\mathrm{f}^{-}\right.\right.$ $\left.\left.{ }^{1}(\mathrm{~A})\right)\right)=\operatorname{int}(\mathrm{A}) \subseteq \mathrm{A}$. Therefore $\operatorname{cl}\left(\operatorname{spint}\left(\mathrm{f}^{-1}(\mathrm{~A})\right)\right)=\mathrm{f}$ ${ }^{1}\left(\mathrm{f}\left(\operatorname{cl}\left(\operatorname{spint}\left(\mathrm{f}^{-1}(\mathrm{~A})\right)\right)\right)\right) \subseteq \mathrm{f}^{-1}(\mathrm{~A})$. Now $\operatorname{cl}\left(\operatorname{int}\left(\mathrm{f}^{-1}(\mathrm{~A})\right)\right) \subseteq \operatorname{cl}(\operatorname{spint}(\mathrm{f}$ $\left.\left.{ }^{-1}(\mathrm{~A})\right)\right) \subseteq \mathrm{f}^{-1}(\mathrm{~A})$. This implies $\mathrm{f}^{-1}(\mathrm{~A})$ is an IFPCS in $\mathrm{X}$ and hence an IFSPGCS in $\mathrm{X}$. Thus $\mathrm{f}$ is an IFCSPG continuous mapping.

Theorem 3.11: Let $f:(X, \tau) \rightarrow(Y, \sigma)$ be a map. Suppose that one of the following properties hold:

(i) $\quad \mathrm{f}(\operatorname{spcl}(\mathrm{A})) \subseteq \operatorname{int}(\mathrm{f}(\mathrm{A}))$ for each IFS A in $\mathrm{X}$

(ii) $\quad \operatorname{spcl}\left(\mathrm{f}^{-1}(\mathrm{~B})\right) \subseteq \mathrm{f}^{-1}(\operatorname{int}(\mathrm{B}))$ for each IFS B in $\mathrm{Y}$

(iii) $\quad \mathrm{f}^{-1}(\mathrm{cl}(\mathrm{B})) \subseteq \operatorname{spint}\left(\mathrm{f}^{-1}(\mathrm{~B})\right)$ for each IFS B in $\mathrm{Y}$

Then $f$ is an IFCSPG continuous mapping.

Proof: (i) $\Rightarrow$ (ii) Let $\mathrm{B} \subseteq \mathrm{Y}$. Then $\mathrm{f}^{-1}(\mathrm{~B})$ is an IFS in $\mathrm{X}$. By hypothesis, $\mathrm{f}\left(\operatorname{spcl}\left(\mathrm{f}^{-1}(\mathrm{~B})\right)\right) \subseteq \operatorname{int}\left(\mathrm{f}\left(\mathrm{f}^{-1}(\mathrm{~B})\right)\right) \subseteq \operatorname{int}(\mathrm{B})$. Now $\operatorname{spcl}(\mathrm{f}$ $\left.{ }^{-1}(\mathrm{~B})\right) \subseteq \mathrm{f}^{-1}\left(\mathrm{f}\left(\operatorname{spcl}\left(\mathrm{f}^{-1}(\mathrm{~B})\right)\right)\right) \subseteq \mathrm{f}^{-1}(\operatorname{int}(\mathrm{B}))$.

(ii) $\Rightarrow$ (iii) is obvious by taking complement in (ii).

Suppose (iii) holds: Let B be an IFCS in Y. Then $\mathrm{cl}(\mathrm{B})=\mathrm{B}$ and $f^{-1}(B)$ is an IFS in $X$. Now $f^{-1}(B)=f^{-1}(c l(B)) \subseteq \operatorname{spint}\left(f^{-}\right.$ $\left.{ }^{1}(\mathrm{~B})\right) \subseteq \mathrm{f}^{-1}(\mathrm{~B})$, by hypothesis. This implies $\mathrm{f}^{-1}(\mathrm{~B})$ is an IFSPOS in $\mathrm{X}$ and hence an IFGSPOS in $\mathrm{X}$. Thus $\mathrm{f}$ is an IFCSPG continuous mapping.

Theorem 3.12: Let $\mathrm{f}:(\mathrm{X}, \tau) \rightarrow(\mathrm{Y}, \sigma)$ be a bijective mapping. Then $\mathrm{f}$ is an IFCSPG continuous mapping if $\operatorname{cl}(\mathrm{f}(\mathrm{A})) \subseteq$ $\mathrm{f}(\operatorname{spint}(\mathrm{A}))$ for every IFS A in X.

Proof: Let $A$ be an IFCS in $Y$. Then $c l(A)=A$ and $f^{-1}(A)$ is an IFS in $X$. By hypothesis $\operatorname{cl}\left(\left(\mathrm{f}\left(\mathrm{f}^{-1}(\mathrm{~A})\right)\right) \subseteq \mathrm{f}\left(\operatorname{spint}\left(\mathrm{f}^{-1}(\mathrm{~A})\right)\right)\right.$. Since $\mathrm{f}$ is onto, $\left.\mathrm{f}^{-1}(\mathrm{~A})\right)=\mathrm{A}$. Therefore $\mathrm{A}=\mathrm{cl}(\mathrm{A})=\operatorname{cl}\left(\mathrm{f}\left(\mathrm{f}^{-}\right.\right.$ $\left.\left.{ }^{1}(A)\right)\right) \subseteq \mathrm{f}\left(\operatorname{spint}\left(\mathrm{f}^{-1}(\mathrm{~A})\right)\right)$. Now $\mathrm{f}^{-1}(\mathrm{~A}) \subseteq \mathrm{f}^{-1}\left(\mathrm{f}\left(\operatorname{spint}\left(\mathrm{f}^{-1}(\mathrm{~A})\right)\right)\right)=$ $\operatorname{spint}\left(\mathrm{f}^{-1}(\mathrm{~A})\right) \subseteq \mathrm{f}^{-1}\left(\right.$ A). Hence $\mathrm{f}^{-1}(\mathrm{~A})$ is an IFSPOS in $\mathrm{X}$ and hence an IFSPGOS in $\mathrm{X}$. Thus $\mathrm{f}$ is an IFCSPG continuous mapping.

Theorem 3.13: If $\mathrm{f}:(\mathrm{X}, \tau) \rightarrow(\mathrm{Y}, \sigma)$ is an IFCSPG continuous mapping, where $\mathrm{X}$ is an $\mathrm{IFSPT}_{1 / 2}$ space, then the following conditions hold: (i) $\operatorname{spcl}\left(\mathrm{f}^{-1}(\mathrm{~B})\right) \subseteq \mathrm{f}^{-1}(\operatorname{int}(\operatorname{spcl}(\mathrm{B})))$ for every IFOS B in

Y

(ii) $\quad \mathrm{f}^{-1}(\operatorname{cl}(\operatorname{spint}(\mathrm{B}))) \subseteq \operatorname{spint}\left(\mathrm{f}^{-1}(\mathrm{~B})\right)$ for every IFCS B in

Y

Proof: (i) Let $\mathrm{B} \subseteq \mathrm{Y}$ be an IFOS. By hypothesis $\mathrm{f}^{-1}(\mathrm{~B})$ is an IFSPGCS in $X$. Since $X$ is an $\operatorname{IFSPT}_{1 / 2}$ space, $f^{-1}(B)$ is an IFSPCS in X. This implies spcl $\left(f^{-1}(B)\right)=f^{-1}(B)=f^{-1}(\operatorname{int}(B)) \subseteq$ $\mathrm{f}^{-1}(\operatorname{int}(\operatorname{spcl}(\mathrm{B})))$.(ii) can be proved easily by taking complement in (i).

Theorem 3.14:(i) If $\mathrm{f}:(\mathrm{X}, \tau) \rightarrow(\mathrm{Y}, \sigma)$ is an IFCSPG continuous mapping and $\mathrm{g}:(\mathrm{Y}, \sigma) \rightarrow(\mathrm{Z}, \eta)$ is an IF continuous mapping, then

(i) go $\mathrm{f:}(\mathrm{X}, \tau) \rightarrow(\mathrm{Z}, \eta)$ is an IFCSPG continuous mapping

(ii) If $\mathrm{f}:(\mathrm{X}, \tau) \rightarrow(\mathrm{Y}, \sigma)$ is an IFCSPG continuous mapping and $g:(Y, \sigma) \rightarrow(Z, \eta)$ is an IFC continuous mapping, then $g$ o $\mathrm{f}:(\mathrm{X}, \tau) \rightarrow(Z, \eta)$ is an IFSPG continuous mapping

(iii)If $\mathrm{f}:(\mathrm{X}, \tau) \rightarrow(\mathrm{Y}, \sigma)$ is an IFSPG irresolute mapping and $\mathrm{g}$ $:(Y, \sigma) \rightarrow(Z, \eta)$ is an IFCSPG continuous mapping, then $g$ of $:(X, \tau) \rightarrow(Z, \eta)$ is an IFCSPG continuous mapping

Proof: (i) Let $A$ be an IFOS in $Z$. Then $g^{-1}(A)$ is an IFOS in $\mathrm{Y}$, since $\mathrm{g}$ is an IF continuous mapping. As $\mathrm{f}$ is an IFCSPG continuous mapping, $\mathrm{f}^{-1}\left(\mathrm{~g}^{-1}(\mathrm{~A})\right)$ is an IFSPGCS in $\mathrm{X}$. Therefore $g$ of is an IFCSPG continuous mapping.

(ii) Let A be an IFOS in Z. Then $\mathrm{g}^{-1}(\mathrm{~A})$ is an IFCS in $\mathrm{Y}$, since $\mathrm{g}$ is an IFC continuous mapping. As $\mathrm{f}$ is an IFCSPG continuous mapping, $\mathrm{f}^{-1}\left(\mathrm{~g}^{-1}(\mathrm{~A})\right)$ is an IFSPGOS in $\mathrm{X}$. Therefore $\mathrm{g}$ of $\mathrm{f}$ is an IFSPG continuous mapping.

(iii) Let $\mathrm{A}$ be an IFOS in Z. Then $\mathrm{g}^{-1}(\mathrm{~A})$ is an IFSPGCS in Y, since $g$ is an IFCSPG continuous mapping. As $f$ is an IFSPG irresolute mapping, $\mathrm{f}^{-1}\left(\mathrm{~g}^{-1}(\mathrm{~A})\right)$ is an IFSPGCS in X. Therefore $\mathrm{g}$ of is an IFCSPG continuous mapping.

Theorem 3.15: For a mapping $\mathrm{f}:(\mathrm{X}, \tau) \rightarrow(\mathrm{Y}, \sigma)$, the following are equivalent, where $\mathrm{X}$ is an IFSPT ${ }_{1 / 2}$ space:

(i) $\quad \mathrm{f}$ is an IFCSPG continuous mapping

(ii) for every IFCS A in $Y, f^{-1}(A)$ is an IFSPGOS in $\mathrm{X}$

(iii) for every IFOS B in $\mathrm{Y}^{-1} \mathrm{f}^{-1}(\mathrm{~B})$ is an IFSPGCS in $\mathrm{X}$

(iv) for any IFCS $\mathrm{A}$ in $\mathrm{Y}$ and for any IFP $\mathrm{p}_{(\alpha, \beta)} \in \mathrm{X}$, if $\mathrm{f}\left(\mathrm{p}_{(\alpha, \beta)}\right)_{\mathrm{q}} \mathrm{A}$, then $\mathrm{p}_{(\alpha, \beta)} \operatorname{spint}\left(\mathrm{f}^{-1}(\mathrm{~A})\right)$

(v) For any IFCS A in Y and for any IFP $p_{(\alpha, \beta)} \in X$, if $\mathrm{f}\left(\mathrm{p}_{(\alpha, \beta)}\right)_{\mathrm{q}} \mathrm{A}$, then there exists an IFSPGOSB such that $\mathrm{p}_{(\alpha, \beta) \mathrm{q}} \mathrm{B}$ and $\mathrm{f}(\mathrm{B}) \subseteq \mathrm{A}$

Proof: (i) $\Leftrightarrow$ (ii) and (ii) $\Leftrightarrow$ (iii) are obvious.

(ii) $\Rightarrow$ (iv) Let $A \subseteq Y$ be an IFCSand let $\mathrm{p}_{(\alpha, \beta)} \in X$. Letf $\left(\mathrm{p}_{(\alpha, \beta)}\right)$ ${ }_{q}$ A. Thenp $(\alpha, \beta) q f^{-1}(A)$. Byhypothesis, $f^{-1}(A)$ is an IFSPGOS in $X$. Since $X$ is an IFSPT $1 / 2$ space, $f^{-1}(A)$ is an IFSPOS in $X$. This implies $\operatorname{spint}\left(\mathrm{f}^{-1}(\mathrm{~A})\right)=\mathrm{f}^{-1}(\mathrm{~A})$. Hencep $(\alpha, \beta) \mathrm{q} \operatorname{spint}\left(\mathrm{f}^{-1}(\mathrm{~A})\right)$.

(iv) $\Rightarrow$ (ii) Let $\mathrm{A} \subseteq \mathrm{Y}$ be an IFCS and let $\mathrm{p}_{(\alpha, \beta)} \in \mathrm{X}$. Let $\mathrm{f}\left(\mathrm{p}_{(\alpha,}\right.$,

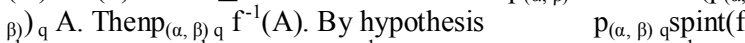
$\left.{ }^{-1}(A)\right)$. That is $\mathrm{f}^{-1}(\mathrm{~A}) \subseteq \operatorname{spint}\left(\mathrm{f}^{-1}(\mathrm{~A})\right)$. But we have $\operatorname{spint}\left(\mathrm{f}^{-1}(\mathrm{~A})\right)$ $\subseteq \mathrm{f}^{-1}(\mathrm{~A})$. Therefore $\mathrm{f}^{-1}(\mathrm{~A})=\operatorname{spint}\left(\mathrm{f}^{-1}(\mathrm{~A})\right)$. Thus $\mathrm{f}^{-1}(\mathrm{~A})$ is an IFSPOS in $\mathrm{X}$ and hence an IFSPGOS in $\mathrm{X}$.

(iv) $\Rightarrow$ (v) Let $A \subseteq Y$ be an IFCS and let $\mathrm{p}_{(\alpha, \beta)} \in \mathrm{X}$. Let $\mathrm{f}\left(\mathrm{p}_{(\alpha,}\right.$ $\left.{ }_{\beta}\right)_{\mathrm{q}}$ A. Thenp $(\alpha, \beta) \mathrm{q} \mathrm{f}^{-1}(\mathrm{~A})$. By hypothesis $\mathrm{p}_{(\alpha, \beta)} \mathrm{q} \operatorname{sint}\left(\mathrm{f}^{-1}(\mathrm{~A})\right)$. Thus $\mathrm{f}^{-1}(\mathrm{~A})$ is an IFSPOS in $\mathrm{X}$ and hence an IFSPGOS in $\mathrm{X}$. Let $\mathrm{f}^{-1}(\mathrm{~A})=\mathrm{B}$. Therefore $\mathrm{p}_{(\alpha, \beta) \mathrm{q}} \mathrm{B}$ and $\mathrm{f}(\mathrm{B})=\mathrm{f}\left(\mathrm{f}^{-1}(\mathrm{~A})\right) \subseteq \mathrm{A}$.

(v) $\Rightarrow$ (iv) Let $A \subseteq Y$ be an IFCS and let $p_{(\alpha, \beta)} \in X$. Let $f\left(p_{(\alpha}\right.$ $\beta)_{q}$ A. Thenp $(\alpha, \beta) q f^{-1}(A)$. By (v) there exists an IFSPGOS B in $X$ such that $p_{(\alpha, \beta) q} B$ and $f(B) \subseteq A$. Let $B=f^{-1}(A)$. Since $X$ is an $\operatorname{IFSPT}_{1 / 2}$ space, $\mathrm{f}^{-1}(\mathrm{~A})$ is an IFSPOS in $\mathrm{X}$. Therefore $\mathrm{p}_{(\alpha}$ в) $q \operatorname{spint}\left(f^{-1}(A)\right)$.

Theorem 3.16: A mapping $\mathrm{f}:(\mathrm{X}, \tau) \rightarrow(\mathrm{Y}, \sigma)$ is an IFCSPG continuous mapping if $\mathrm{f}^{-1}(\operatorname{spcl}(\mathrm{B})) \subseteq \operatorname{int}\left(\mathrm{f}^{-1}(\mathrm{~B})\right)$ for every IFS $\mathrm{B}$ in $\mathrm{Y}$. 
Proof: Let $\mathrm{B} \subseteq \mathrm{Y}$ be an IFCS. Then $\mathrm{cl}(\mathrm{B})=\mathrm{B}$. Since every IFCS is an IFSPCS, $\operatorname{spcl}(\mathrm{B})=\mathrm{B}$. Now by hypothesis, $\mathrm{f}^{-1}(\mathrm{~B})=$ $\mathrm{f}^{-1}(\operatorname{spcl}(\mathrm{B})) \subseteq \operatorname{int}\left(\mathrm{f}^{-1}(\mathrm{~B})\right) \subseteq \mathrm{f}^{-1}(\mathrm{~B})$. This implies $\mathrm{f}^{-1}(\mathrm{~B})$ is an IFOS in $\mathrm{X}$. Therefore $\mathrm{f}$ is an IFC continuous mapping. Then by Theorem 3.3, $\mathrm{f}$ is an IFCSPG continuous mapping.

Theorem 3.17: A mapping $\mathrm{f}:(\mathrm{X}, \tau) \rightarrow(\mathrm{Y}, \sigma)$ is an IFCSPG continuous mapping, where $\mathrm{X}$ is an $\mathrm{IFSPT}_{1 / 2}$ space if and only if $\mathrm{f}^{-1}(\operatorname{spcl}(\mathrm{B})) \subseteq \operatorname{spint}\left(\mathrm{f}^{-1}(\mathrm{cl}(\mathrm{B}))\right)$ for every IFS Bin $\mathrm{Y}$.

Proof: Necessity: Let $\mathrm{B} \subseteq \mathrm{Y}$ be an IFS. Then cl(B) is an IFCS in Y. By hypothesisf $f^{-1}(\mathrm{cl}(\mathrm{B}))$ is an IFSPGOS in X. Since $\mathrm{X}$ is an $\operatorname{IFSPT}_{1 / 2}$ space, $\mathrm{f}^{-1}(\mathrm{cl}(\mathrm{B}))$ is an IFSPOS in $\mathrm{X}$. Therefore $\mathrm{f}^{-}$ ${ }^{1}(\operatorname{spcl}(\mathrm{B})) \subseteq \mathrm{f}^{-1}(\mathrm{cl}(\mathrm{B}))=\operatorname{spint}\left(\mathrm{f}^{-1}(\mathrm{cl}(\mathrm{B}))\right)$.

Sufficiency: Let $\mathrm{B} \subseteq \mathrm{Y}$ be an IFCS. Then $\operatorname{cl}(\mathrm{B})=\mathrm{B}$. By hypothesis, $\mathrm{f}^{-1}(\operatorname{spcl}(\mathrm{B})) \subseteq \operatorname{spint}\left(\mathrm{f}^{-1}(\mathrm{cl}(\mathrm{B}))\right)=\operatorname{spint}\left(\mathrm{f}^{-1}(\mathrm{~B})\right)$. But $\operatorname{spcl}(B)=B$. Therefore $\mathrm{f}^{-1}(\mathrm{~B})=\mathrm{f}^{-1}(\operatorname{spcl}(\mathrm{B})) \subseteq \operatorname{spint}\left(\mathrm{f}^{-1}(\mathrm{~B})\right)$ $\subseteq \mathrm{f}^{-1}(\mathrm{~B})$. This implies $\mathrm{f}^{-1}(\mathrm{~B})$ is an IFSPOS in $\mathrm{X}$ and hence an IFSPGOS in $\mathrm{X}$. Hence $\mathrm{f}$ is an IFCSPG continuous mapping.

Theorem 3.18: An IF continuous mappingf $:(X, \tau) \rightarrow(Y, \sigma)$ is an IFCSPG continuous mapping if $\operatorname{IFSPGO}(\mathrm{X})=$ $\operatorname{IFSPGC}(\mathrm{X})$

Proof: Let $A \subseteq Y$ be an IFOS. By hypothesis, $f^{-1}(A)$ is an IFOS in $\mathrm{X}$ and hence is an IFSPGOS in $\mathrm{X}$. Since IFSPGO(X) $=\operatorname{IFSPGC}(\mathrm{X}), \mathrm{f}^{-1}(\mathrm{~A})$ is an IFSPGCS in $\mathrm{X}$. Therefore $\mathrm{f}$ is an IFCSPG continuous mapping.

\section{INTUITIONISTIC FUZZY ALMOST CONTRA SEMIPRE GENERALIZED CONTINUOUS MAPPINGS}

In this section we have introduced intuitionistic fuzzy almost contra semipre generalized continuous mappings and studied some of its properties.

Definition 4.1: A mapping $\mathrm{f}:(\mathrm{X}, \tau) \rightarrow(\mathrm{Y}, \sigma)$ is said to be an intuitionistic fuzzy almost contra semipre generalized continuous mapping (IFaCSPG continuous mapping for short) if $\mathrm{f}^{-1}(\mathrm{~A})$ is an IFSPGCS in $\mathrm{X}$ for every IFROS A in $\mathrm{Y}$.

Example 4.2: Let $\mathrm{X}=\{\mathrm{a}, \mathrm{b}\}, \mathrm{Y}=\{\mathrm{u}, \mathrm{v}\}$ and $\mathrm{G}_{1}=\langle\mathrm{x},(0.5$, $0.4),(0.5,0.6)\rangle, \mathrm{G}_{2}=\langle\mathrm{y},(0.4,0.2),(0.6,0.7)\rangle$. Then $\tau=\{0$, $\mathrm{G}_{1,1}, 1_{\sim}$ and $\sigma=\left\{0_{\sim}, \mathrm{G}_{2,}, 1_{\sim}\right\}$ are IFTs on $\mathrm{X}$ and $\mathrm{Y}$ respectively. Define a mapping $\mathrm{f}:(\mathrm{X}, \tau) \rightarrow(\mathrm{Y}, \sigma)$ by $\mathrm{f}(\mathrm{a})=\mathrm{u}$ and $\mathrm{f}(\mathrm{b})=\mathrm{v}$. Then $\mathrm{f}$ is an IFaCSPG continuous mapping.

Theorem 4.3: Every IFC continuous mapping is an IFaCSPG continuous mapping but not conversely.

Proof: Let $A \subseteq Y$ be an IFROS. Since every IFROS is an IFOS, $A$ is an IFOS in $Y$. Then $\mathrm{f}^{-1}(\mathrm{~A})$ is an IFCS in $\mathrm{X}$, by hypothesis. Hence $\mathrm{f}^{-1}(\mathrm{~A})$ is an IFSPGCS in $\mathrm{X}$. Therefore $\mathrm{f}$ is an IFaCSPG continuous mapping.

Example 4.4: Let $\mathrm{X}=\{\mathrm{a}, \mathrm{b}\}, \mathrm{Y}=\{\mathrm{u}, \mathrm{v}\}$ and $\mathrm{G}_{1}=\langle\mathrm{x},(0.5$, $0.4),(0.5,0.6)\rangle, G_{2}=\langle y,(0.4,0.2),(0.6,0.7)\rangle$. Then $\tau=\{0$, $\left.\mathrm{G}_{1}, 1_{\sim}\right\}$ and $\sigma=\left\{0_{\sim}, \mathrm{G}_{2}, 1_{\sim}\right\}$ are IFTs on $\mathrm{X}$ and $\mathrm{Y}$ respectively. Define a mapping $\mathrm{f}:(\mathrm{X}, \tau) \rightarrow(\mathrm{Y}, \sigma)$ by $\mathrm{f}(\mathrm{a})=\mathrm{u}$ and $\mathrm{f}(\mathrm{b})=\mathrm{v}$. Then $\mathrm{f}$ is an IFaCSPG continuous mapping but not an IFC continuous mapping.

Theorem 4.5: Every IFC $\alpha$ continuous mapping is an IFaCSPG continuous mapping but not conversely.

Proof: Let $A \subseteq Y$ be an IFROS. Since every IFROS is an IFOS, $A$ is an IFOS in Y. Then $\mathrm{f}^{-1}(\mathrm{~A})$ is an IF $\alpha \mathrm{CS}$ in $\mathrm{X}$, by hypothesis. Hence $f^{-1}(A)$ is an IFSPGCS in $X$. Therefore $f$ is an IFaCSPG continuous mapping.
Example 4.6: Let $X=\{a, b\}, Y=\{u, v\}$ and $G_{1}=\langle x,(0.5$, $0.4),(0.5,0.6)\rangle, \mathrm{G}_{2}=\langle\mathrm{y},(0.4,0.2),(0.6,0.7)\rangle$. Then $\tau=\{0$, $\left.\mathrm{G}_{1}, 1_{\sim}\right\}$ and $\sigma=\left\{0_{\sim}, \mathrm{G}_{2}, 1_{\sim}\right\}$ are IFT on $\mathrm{X}$ and $\mathrm{Y}$ respectively. Define a mapping $\mathrm{f}:(\mathrm{X}, \tau) \rightarrow(\mathrm{Y}, \sigma)$ by $\mathrm{f}(\mathrm{a})=\mathrm{u}$ and $\mathrm{f}(\mathrm{b})=\mathrm{v}$. Then $f$ is an IFaCSPG continuous mapping but not an IFCacontinuos mapping.

Theorem 4.7: Every IFCP continuous mapping is an IFaCSPG continuous mapping but not conversely.

Proof: Let $A \subseteq Y$ be an IFROS. Since every IFROS is an IFOS, $A$ is an IFOS in $Y$. Then $\mathrm{f}^{-1}(\mathrm{~A})$ is an IFPCS in $\mathrm{X}$, by hypothesis. Hence $\mathrm{f}^{-1}(\mathrm{~A})$ is an IFSPGCS in $\mathrm{X}$. Therefore $\mathrm{f}$ is an IFaCSPG continuous mapping.

Example 4.8: Let $X=\{a, b\}, Y=\{u, v\}$ and $G_{1}=\langle x,(0.5$, $0.6),(0.5,0.4)\rangle, \mathrm{G}_{2}=\langle\mathrm{x},(0.2,0.1),(0.8,0.9)\rangle$ and $\mathrm{G}_{3}=\langle\mathrm{y}$, $(0.2,0.3),(0.8,0.7)\rangle$. Then $\tau=\left\{0_{\sim}, G_{1}, G_{2}, 1_{\sim}\right\}$ and $\sigma=\left\{0_{\sim}\right.$, $\left.\mathrm{G}_{3}, 1_{\sim}\right\}$ are IFTs on $\mathrm{X}$ and $\mathrm{Y}$ respectively. Define a mapping $\mathrm{f}$ : $(\mathrm{X}, \tau) \rightarrow(\mathrm{Y}, \sigma)$ by $\mathrm{f}(\mathrm{a})=\mathrm{u}$ and $\mathrm{f}(\mathrm{b})=\mathrm{v}$. Then $\mathrm{f}$ is an IFaCSPG continuous mapping but not an IFCP continuous mapping.

Theorem 4.9: Every IFCSPG continuous mapping is an IFaCSPG continuous mapping but not conversely.

Proof: Let $\mathrm{f}:(\mathrm{X}, \tau) \rightarrow(\mathrm{Y}, \sigma)$ be an IFCSPG continuous mapping. Let $A \subseteq Y$ be an IFROS. Then $A$ is an IFOS in $Y$. By hypothesis, $\mathrm{f}^{-1}(\mathrm{~A})$ is an IFSPGCS in X. Hence $\mathrm{f}$ is an IFaCSPG continuous mapping.

Example 4.10: Let $\mathrm{X}=\{\mathrm{a}, \mathrm{b}\}, \mathrm{Y}=\{\mathrm{u}, \mathrm{v}\}$ and $\mathrm{G}_{1}=\langle\mathrm{x},(0.5$, $0.6),(0.5,0.4)\rangle, \mathrm{G}_{2}=\langle\mathrm{y},(0.8,0.7),(0.2,0.3)\rangle$ and $\mathrm{G}_{3}=\langle\mathrm{y}$, $(0.5,0.5),(0.5,0.5)\rangle$.Then $\tau=\left\{0_{\sim}, \mathrm{G}_{1}, 1_{\sim}\right\}$ and $\sigma=\left\{0_{\sim}, \mathrm{G}_{2}\right.$, $\left.\mathrm{G}_{3}, 1_{\sim}\right\}$ are IFTs on $\mathrm{X}$ and $\mathrm{Y}$ respectively. Define a mapping $\mathrm{f}$ : $(\mathrm{X}, \tau) \rightarrow(\mathrm{Y}, \sigma)$ by $\mathrm{f}(\mathrm{a})=\mathrm{u}$ and $\mathrm{f}(\mathrm{b})=\mathrm{v}$. Then $\mathrm{f}$ is an IFaCSPG continuous mapping but not an IFCSPG continuous mapping.

Theorem 4.11: If $\mathrm{f}:(\mathrm{X}, \tau) \rightarrow(\mathrm{Y}, \sigma)$ is a mapping, then the following are equivalent:

(i) $\mathrm{f}$ is an IFaCSPG continuous mapping,

(ii) $\quad \mathrm{f}^{-1}(\mathrm{~A}) \in \operatorname{IFSPGO}(\mathrm{X})$ for every $\mathrm{A} \in \operatorname{IFRC}(\mathrm{Y})$.

Proof: (i) $\Rightarrow$ (ii) Let $A$ be an IFRCS in $Y$. Then $A^{c}$ is an IFROS in $\mathrm{Y}$. By hypothesis, $\mathrm{f}^{-1}\left(\mathrm{~A}^{\mathrm{c}}\right)$ is an IFSPGCS in $\mathrm{X}$. Therefore $\mathrm{f}^{-1}(\mathrm{~A})$ is an IFSPGOS in $\mathrm{X}$.

(ii) $\Rightarrow$ (i) Let $A$ be an IFROS in $Y$. Then $A^{c}$ is an IFRCS in $Y$. By hypothesis, $\mathrm{f}^{-1}\left(\mathrm{~A}^{\mathrm{c}}\right)$ is an IFSPGOS in $\mathrm{X}$. Therefore $\mathrm{f}^{-1}(\mathrm{~A})$ is an IFSPGCS in X. Hence $\mathrm{f}$ is an IFaCSPG continuous mapping.

The relation between various types of intuitionistic fuzzy contra continuity is given in the following diagram. In this diagram cts means continuous mapping.

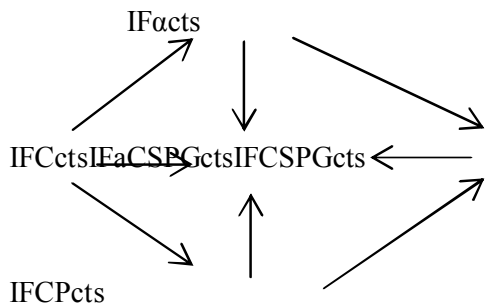

The reverse implications are not true in general in the above diagram. 
Theorem 4.12: If $\mathrm{f}:(\mathrm{X}, \tau) \rightarrow(\mathrm{Y}, \sigma)$ is a mapping, where $\mathrm{X}$ is an IFSPT $_{1 / 2}$ space, then the following are equivalent:

(i) $\quad \mathrm{f}$ is an IFaCSPG continuous mapping

(ii) $\quad \mathrm{f}^{-1}(\mathrm{~A}) \in \operatorname{IFSPGO}(\mathrm{X})$ for every $\mathrm{A} \in \operatorname{IFRC}(\mathrm{Y})$

(iii) $\quad \mathrm{f}^{-1}(\operatorname{int}(\operatorname{cl}(\mathrm{G}))) \in \operatorname{IFSPGC}(\mathrm{X})$ for every IFOS $\mathrm{G} \subseteq \mathrm{Y}$

(iv) $\quad \mathrm{f}^{-1}(\operatorname{cl}(\operatorname{int}(\mathrm{H}))) \in \mathrm{IFSPGO}(\mathrm{X})$ for every IFCS $\mathrm{H} \subseteq \mathrm{Y}$

Proof: (i) $\Leftrightarrow$ (ii) is obvious from the Theorem 4.12.

(i) $\Rightarrow$ (iii) Let $G$ be any IFOS in $Y$. Then $\operatorname{int}(\operatorname{cl}(G))$ is an IFROS in Y. By hypothesis, $\mathrm{f}^{-1}(\operatorname{int}(\mathrm{cl}(\mathrm{G})))$ is an IFSPGCS in $X$. Hencef ${ }^{-1}(\operatorname{int}(\operatorname{cl}(G))) \in \operatorname{IFSPGC}(X)$.

(iii) $\Rightarrow$ (i) Let A be any IFROS in Y. Then A is an IFOS in Y. By hypothesis, we have $\mathrm{f}^{-1}(\operatorname{int}(\operatorname{cl}(\mathrm{A}))) \in \operatorname{IFSPGC}(\mathrm{X})$. That is $\mathrm{f}^{-1}(\mathrm{~A}) \in \operatorname{IFSPGC}(\mathrm{X})$, since $\operatorname{int}(\mathrm{cl}(\mathrm{A}))=\mathrm{A}$. Hence $\mathrm{f}$ is an IFaCSPG continuous mapping.

(ii) $\Leftrightarrow$ (iv) is similar to (i) $\Leftrightarrow$ (iii).

\section{INTUITIONISTIC FUZZY CONTRA SEMIPRE GENERALIZED OPEN MAPPINGS}

In this section we have introduced intuitionistic fuzzy contra semipre generalized openmappings. We have investigated some of its properties.

Definition 5.1: A mapping $f:(X, \tau) \rightarrow(Y, \sigma)$ is said to be an intuitionistic fuzzy contra semipre generalized open mapping (IFCSPGOM for short) if $\mathrm{f}(\mathrm{A})$ is an IFSPGCS in Y for every IFOS A in $\mathrm{X}$.

Example 5.2: Let $\mathrm{X}=\{\mathrm{a}, \mathrm{b}\}, \mathrm{Y}=\{\mathrm{u}, \mathrm{v}\}$ and $\mathrm{G}_{1}=\langle\mathrm{x},(0.4$, $0.2),(0.6,0.7)\rangle, \mathrm{G}_{2}=\langle\mathrm{y},(0.5,0.4),(0.5,0.6)\rangle$. Then $\tau=\{0$, $\left.\mathrm{G}_{1}, 1_{\sim}\right\}$ and $\sigma=\left\{0_{\sim}, \mathrm{G}_{2}, 1_{\sim}\right\}$ are IFTs on $\mathrm{X}$ and $\mathrm{Y}$ respectively. Define a mapping $\mathrm{f}:(\mathrm{X}, \tau) \rightarrow(\mathrm{Y}, \sigma)$ by $\mathrm{f}(\mathrm{a})=\mathrm{u}$ and $\mathrm{f}(\mathrm{b})=\mathrm{v}$. Then $\mathrm{f}$ is an IFCSPGOM.

Theorem 5.3: For a bijective mapping $f:(X, \tau) \rightarrow(Y, \sigma)$, where $\mathrm{Y}$ is an $\mathrm{IFSPT}_{1 / 2}$ space, the following statements are equivalent:

(i) $\mathrm{f}$ is an IFCSPGOM

(ii) for every IFCS A in X, $\mathrm{f}(\mathrm{A})$ is an IFSPGOS in $\mathrm{Y}$

(iii) for every IFOS $\mathrm{B}$ in $\mathrm{X}, \mathrm{f}(\mathrm{B})$ is an IFSPGCS in $\mathrm{Y}$

(iv) for any IFCS $A$ in $X$ and for any IFP $p(\alpha, \beta) \in Y$, if $f$

${ }^{-1}\left(\mathrm{p}_{(\alpha, \beta)}\right)_{\mathrm{q}} \mathrm{A}$, thenp $\mathrm{p}_{(\alpha, \beta)} \mathrm{q} \operatorname{sint}(\mathrm{f}(\mathrm{A}))$

(v) For any IFCS $A$ in $X$ and for any $p_{(\alpha, \beta)} \in \mathrm{Y}$, if $\mathrm{f}^{-}$

${ }^{1}\left(p_{(\alpha, \beta)}\right)_{q} A$, then there existsan IFSPGOS B such that $\mathrm{p}_{(\alpha, \beta) q} B$ and $\mathrm{f}^{-1}(\mathrm{~B}) \subseteq \mathrm{A}$

Proof: (i) $\Rightarrow$ (ii) Let $A$ be an IFCS in $X$. Then $A^{c}$ is an IFOS in X. By hypothesis, $f\left(A^{c}\right)$ is an IFSPGCS in $Y$. That is $f(A)^{c}$ is an IFSPGCS in Y. Hence $\mathrm{f}(\mathrm{A})$ is an IFSPGOS in $\mathrm{Y}$.

(ii) $\Rightarrow$ (i) Let $A$ be an IFOS in X. Then $A^{c}$ is an IFCS in X. By hypothesis, $f\left(A^{c}\right)=(f(A))^{c}$ is an IFSPGOS in Y. Hence $f(A)$ is an IFSPGCS in Y. Thus $\mathrm{f}$ is an IFCSPGOM.

(ii) $\Leftrightarrow$ (iii) is obvious.

(ii) $\Rightarrow$ (iv) Let $A \subseteq X$ be an IFCSand let $p_{(\alpha, \beta)} \in Y$. Assume that $\mathrm{f}^{-1}\left(\mathrm{p}_{(\alpha, \beta)}\right)_{q} \mathrm{~A}$. Then $\mathrm{p}_{(\alpha, \beta) q} \mathrm{f}(\mathrm{A})$. By hypothesis, $\mathrm{f}(\mathrm{A})$ is an IFSPGOS in $Y$. Since $Y$ is an $\operatorname{IFSPT}_{1 / 2}$ space, $f(A)$ is an IFSPOS in $Y$. This implies spint $(\mathrm{f}(\mathrm{A}))=\mathrm{f}(\mathrm{A})$. Hence $\mathrm{p}_{(\alpha, \beta)}$ ${ }_{\mathrm{q}} \operatorname{spint}(\mathrm{f}(\mathrm{A}))$.

(iv) $\Rightarrow$ (ii) Let $A \subseteq X$ be an IFCS and let $\mathrm{p}_{(\alpha, \beta)} \in \mathrm{Y}$. Assume that $\mathrm{f}^{-1}\left(\mathrm{p}_{(\alpha, \beta)}\right)_{q} \mathrm{~A}$. Then $\mathrm{p}_{(\alpha, \beta) q} \mathrm{f}(\mathrm{A})$. By hypothesis $\mathrm{p}_{(\alpha, \beta)}$ ${ }_{\mathrm{q}} \operatorname{spint}(\mathrm{f}(\mathrm{A}))$. That is $\mathrm{f}(\mathrm{A}) \subseteq \operatorname{spint}(\mathrm{f}(\mathrm{A})) \subseteq \mathrm{f}(\mathrm{A})$. Therefore $\mathrm{f}(\mathrm{A})$ $=\operatorname{spint}(\mathrm{f}(\mathrm{A}))$ is an IFSPOS in $\mathrm{Y}$ and hence an IFSPGOS in $\mathrm{Y}$. (iv) $\Rightarrow$ (v) Let $A \subseteq X$ be an IFCS and let $p_{(\alpha, \beta)} \in Y$. Assume that $\mathrm{f}^{-1}\left(\mathrm{p}_{(\alpha, \beta)}\right)_{\mathrm{q}} \mathrm{A}$. Then $\mathrm{p}_{(\alpha, \beta) q} \mathrm{f}(\mathrm{A})$. This implies $\mathrm{p}_{(\alpha, \beta)}$ ${ }_{q} \operatorname{spint}(f(A))$. Thus $f(A)$ is an IFSPOS in $Y$ and hence an IFSPGOS in $Y$. Let $\mathrm{f}(\mathrm{A})=\mathrm{B}$. Therefore $\mathrm{p}_{(\alpha, \beta) q} \mathrm{~B}$ and $\mathrm{f}^{-1}(\mathrm{~B})=$ $\mathrm{f}^{-1}(\mathrm{f}(\mathrm{A})) \subseteq \mathrm{A}$. (v) $\Rightarrow$ (iv) Let $A \subseteq X$ be an IFCS and let $p_{(\alpha, \beta)} \in Y$. Assume that $\mathrm{f}^{-1}\left(\mathrm{p}_{(\alpha, \beta)}\right)_{q} \mathrm{~A}$. Thenp $(\alpha, \beta) q \mathrm{f}(\mathrm{A})$. By hypothesis there exists an IFSPGOS B in Y such that $\mathrm{p}_{(\alpha, \beta) q} B$ and $\mathrm{f}^{-1}(\mathrm{~B}) \subseteq \mathrm{A}$. Let $\mathrm{B}$ $=f(A)$. Then $p_{(\alpha, \beta) q} f(A)$. Since $Y$ is an IFSPT $T_{1 / 2}$ space, $f(A)$ is an IFSPOS in $Y$. Therefore $\mathrm{p}_{(\alpha, \beta)} \operatorname{spint}(\mathrm{f}(\mathrm{A}))$.

Theorem 5.4: Let $\mathrm{f}:(\mathrm{X}, \tau) \rightarrow(\mathrm{Y}, \sigma)$ be a bijective mapping. Suppose that one of the following properties hold:

(i) $\quad \mathrm{f}(\mathrm{cl}(\mathrm{B})) \subseteq \operatorname{int}(\operatorname{spcl}(\mathrm{f}(\mathrm{B})))$ for each IFS B in $\mathrm{X}$

(ii) $\quad \operatorname{cl}(\operatorname{spint}(f(B))) \subseteq f(\operatorname{int}(B))$ for each IFS B in $X$

(iii) $\quad \mathrm{f}^{-1}(\operatorname{cl}(\operatorname{spint}(\mathrm{A}))) \subseteq \operatorname{int}\left(\mathrm{f}^{-1}(\mathrm{~A})\right)$ for each IFS A in $\mathrm{Y}$

(iv) $\quad \mathrm{f}^{-1}(\mathrm{cl}(\mathrm{A})) \subseteq \operatorname{int}\left(\mathrm{f}^{-1}(\mathrm{~A})\right)$ for each IFSPOS $\mathrm{A}$ in $\mathrm{Y}$

Then $\mathrm{f}$ is an IFCSPGOM.

Proof: (i) $\Rightarrow$ (ii) is obvious by taking the complement in (i).

(ii) $\Rightarrow$ (iii) Let $A \subseteq Y$. Put $B=f^{-1}(A)$ in $X$. This implies $A=$

$\mathrm{f}(\mathrm{B})$ in $\mathrm{Y}$. Now $\operatorname{cl}(\operatorname{spint}(\mathrm{A}))=\operatorname{cl}(\operatorname{spint}(\mathrm{f}(\mathrm{B}))) \subseteq \mathrm{f}(\operatorname{int}(\mathrm{B}))$ by (ii). Therefore $\mathrm{f}^{-1}(\operatorname{cl}(\operatorname{spint}(\mathrm{A}))) \subseteq \mathrm{f}^{-1}(\mathrm{f}(\operatorname{int}(\mathrm{B})))=\operatorname{int}(\mathrm{B})=\operatorname{int}(\mathrm{f}$ $\left.{ }^{-1}(\mathrm{~A})\right)$.

(iii) $\Rightarrow$ (iv) Let $\mathrm{A} \subseteq \mathrm{Y}$ be an IFSPOS. Then $\operatorname{spint}(\mathrm{A})=\mathrm{A}$. By hypothesis, $\mathrm{f}^{-1}(\mathrm{cl}(\operatorname{spint}(\mathrm{A}))) \subseteq \operatorname{int}\left(\mathrm{f}^{-1}(\mathrm{~A})\right)$. Therefore $\mathrm{f}^{-1}(\mathrm{cl}(\mathrm{A}))$ $\subseteq \operatorname{int}\left(f^{-1}(\mathrm{~A})\right)$.

Suppose (iv) holds: Let A be an IFOS in X. Then $\mathrm{f}(\mathrm{A})$ is an IFS in $\mathrm{Y}$ and $\operatorname{spint}(\mathrm{f}(\mathrm{A}))$ is an IFSPOS in $\mathrm{Y}$. Hence by hypothesis, we have $\mathrm{f}^{-1}(\operatorname{cl}(\operatorname{spint}(\mathrm{f}(\mathrm{A})))) \subseteq \operatorname{int}\left(\mathrm{f}^{-1}(\operatorname{spint}(\mathrm{f}(\mathrm{A})))\right)$ $\subseteq \operatorname{int}\left(\mathrm{f}^{-1}(\mathrm{f}(\mathrm{A}))\right)=\operatorname{int}(\mathrm{A}) \subseteq \mathrm{A}$. Therefore $\operatorname{cl}(\operatorname{spint}(\mathrm{f}(\mathrm{A})))=\mathrm{f}\left(\mathrm{f}^{-}\right.$ $\left.{ }^{1}(\operatorname{cl}(\operatorname{spint}(\mathrm{f}(\mathrm{A}))))\right) \subseteq \mathrm{f}(\mathrm{A}) . \operatorname{Now} \operatorname{cl}(\operatorname{int}(\mathrm{f}(\mathrm{A}))) \subseteq \operatorname{cl}(\operatorname{spint}(\mathrm{f}(\mathrm{A})))$ $\subseteq \mathrm{f}(\mathrm{A})$. This implies $\mathrm{f}(\mathrm{A})$ is an IFPCS in $\mathrm{Y}$ and hence an IFSPGCS in Y. Thus $\mathrm{f}$ is an IFCSPGOM.

Theorem 5.5: Let $f:(X, \tau) \rightarrow(Y, \sigma)$ be a bijective mapping. Suppose that one of the following properties hold:

(i) $\quad \mathrm{f}^{-1}(\operatorname{spcl}(\mathrm{A})) \subseteq \operatorname{int}\left(\mathrm{f}^{-1}(\mathrm{~A})\right)$ for each IFS $\mathrm{A}$ in $\mathrm{Y}$

(ii) $\quad \operatorname{spcl}(\mathrm{f}(\mathrm{B})) \subseteq \mathrm{f}(\operatorname{int}(\mathrm{B}))$ for each IFS $\mathrm{B}$ in $\mathrm{X}$

(iii) $\quad \mathrm{f}(\mathrm{cl}(\mathrm{B})) \subseteq \operatorname{spint}(\mathrm{f}(\mathrm{B}))$ for each IFS B in $\mathrm{X}$

Then $\mathrm{f}$ is an IFCSPGOM.

Proof: (i) $\Rightarrow$ (ii) Let $B \subseteq X$. Then $f(B)$ is an IFS in $Y$. By hypothesis, $\mathrm{f}^{-1}(\operatorname{spcl}(\mathrm{f}(\mathrm{B}))) \subseteq \operatorname{int}\left(\mathrm{f}^{-1}(\mathrm{f}(\mathrm{B}))\right)=\operatorname{int}(\mathrm{B})$. Now $\operatorname{spcl}(\mathrm{f}(\mathrm{B}))=\mathrm{f}\left(\mathrm{f}^{-1}(\operatorname{spcl}(\mathrm{f}(\mathrm{B})))\right) \subseteq \mathrm{f}(\operatorname{int}(\mathrm{B}))$.

(ii) $\Rightarrow$ (iii) is obvious by taking complement in (ii).

Suppose (iii) holds. Let B be an IFCS in X. Then $\mathrm{cl}(\mathrm{B})=\mathrm{B}$ and $\mathrm{f}(\mathrm{B})$ is an IFS in $\mathrm{Y}$. Now $\mathrm{f}(\mathrm{B})=\mathrm{f}(\mathrm{cl}(\mathrm{B})) \subseteq \operatorname{spint}(\mathrm{f}(\mathrm{B})) \subseteq$ $\mathrm{f}(\mathrm{B})$, by hypothesis. This implies $\mathrm{f}(\mathrm{B})$ is an IFSPOS in $\mathrm{Y}$ and hence an IFSPGOS in $\mathrm{Y}$. Thus $\mathrm{f}$ is an IFCSPGOM by Theorem 5.3 .

Theorem 5.6: Let $\mathrm{f}:(\mathrm{X}, \tau) \rightarrow(\mathrm{Y}, \sigma)$ be a bijective mapping. Then $\mathrm{f}$ is an IFCSPGOM if $\operatorname{cl}\left(\mathrm{f}^{-1}(\mathrm{~A})\right) \subseteq \mathrm{f}^{-1}(\operatorname{spint}(\mathrm{A}))$ for every IFS $\mathrm{A}$ in $\mathrm{Y}$.

Proof: Let $A$ be an IFCS in $X$. Then $\operatorname{cl}(A)=A$ and $f(A)$ is an IFS in $Y$. By hypothesis $\operatorname{cl}\left(\mathrm{f}^{-1}(\mathrm{f}(\mathrm{A}))\right) \subseteq \mathrm{f}^{-1}(\operatorname{spint}(\mathrm{f}(\mathrm{A})))$. Therefore $\mathrm{A}=\operatorname{cl}(\mathrm{A})=\operatorname{cl}\left(\mathrm{f}^{-1}(\mathrm{f}(\mathrm{A}))\right) \subseteq \mathrm{f}^{-1}(\operatorname{spint}(\mathrm{f}(\mathrm{A})))$. Now $\mathrm{f}(\mathrm{A}) \subseteq \mathrm{f}\left(\mathrm{f}^{-1}(\operatorname{spint}(\mathrm{f}(\mathrm{A})))\right)=\operatorname{spint}(\mathrm{f}(\mathrm{A})) \subseteq \mathrm{f}(\mathrm{A})$. Hence $\mathrm{f}(\mathrm{A})$ is an IFSPOS in $\mathrm{Y}$ and hence an IFSPGOS in $\mathrm{Y}$. Thus $\mathrm{f}$ is an IFCSPGOM by Theorem 5.3.

Theorem 5.7: If $\mathrm{f}:(\mathrm{X}, \tau) \rightarrow(\mathrm{Y}, \sigma)$ is an IFCSPGOM, where $\mathrm{Y}$ is an $\mathrm{IFSPT}_{1 / 2}$ space, then the following conditions are hold: (i) $\quad \operatorname{spcl}(\mathrm{f}(\mathrm{B})) \subseteq \mathrm{f}(\operatorname{int}(\operatorname{spcl}(\mathrm{B})))$ for every IFOS B in $\mathrm{X}$ (ii) $\quad \mathrm{f}(\mathrm{cl}(\operatorname{spint}(\mathrm{B}))) \subseteq \operatorname{spint}(\mathrm{f}(\mathrm{B}))$ for every IFCS B in $\mathrm{X}$

Proof: (i) Let $\mathrm{B} \subseteq \mathrm{X}$ be an IFOS. Then $\operatorname{int}(\mathrm{B})=\mathrm{B}$. By hypothesis $\mathrm{f}(\mathrm{B})$ is an IFSPGCS in $\mathrm{Y}$. Since $\mathrm{Y}$ is an $\mathrm{IFSPT}_{1 / 2}$ space, $\mathrm{f}(\mathrm{B})$ is an IFSPCS in Y. This implies $\operatorname{spcl}(\mathrm{f}(\mathrm{B}))=\mathrm{f}(\mathrm{B})$ $=\mathrm{f}(\operatorname{int}(\mathrm{B})) \subseteq \mathrm{f}(\operatorname{int}(\operatorname{spcl}(\mathrm{B})))$.

(ii) can be proved easily by taking complement in (i).

Theorem 5.8: A mapping $\mathrm{f}:(\mathrm{X}, \tau) \rightarrow(\mathrm{Y}, \sigma)$ is an IFCSPGOM if $\mathrm{f}(\operatorname{spcl}(\mathrm{B})) \subseteq \operatorname{int}(\mathrm{f}(\mathrm{B}))$ for every IFS B in X. 
Proof: Let $\mathrm{B} \subseteq \mathrm{X}$ be an IFCS. Then $\mathrm{cl}(\mathrm{B})=\mathrm{B}$. Since every IFCS is an IFSPCS, $\operatorname{spcl}(\mathrm{B})=\mathrm{B}$. Now by hypothesis, $\mathrm{f}(\mathrm{B})=$ $\mathrm{f}(\operatorname{spcl}(\mathrm{B})) \subseteq \operatorname{int}(\mathrm{f}(\mathrm{B})) \subseteq \mathrm{f}(\mathrm{B})$. This implies $\mathrm{f}(\mathrm{B})$ is an IFOS in $Y$. Therefore $f(B)$ is an IFSPGOS in $Y$. Hence $f$ is an IFCSPGOM.

Theorem 5.9: A mapping $\mathrm{f}:(\mathrm{X}, \tau) \rightarrow(\mathrm{Y}, \sigma)$ is an IFCSPGOM, where $\mathrm{Y}$ is an IFSPT $_{1 / 2}$ space if and only if $\mathrm{f}(\operatorname{spcl}(\mathrm{B})) \subseteq \operatorname{spint}(\mathrm{f}(\mathrm{cl}(\mathrm{B})))$ for every IFS B in $\mathrm{X}$.

Proof: Necessity: Let $B \subseteq X$ be an IFS. Then cl(B) is an IFCS in X. By hypothesis $\mathrm{f}(\mathrm{cl}(\mathrm{B}))$ is an IFSPGOS in Y. Since Y is an $\operatorname{IFSPT}_{1 / 2}$ space, $\mathrm{f}(\mathrm{cl}(\mathrm{B}))$ is an IFSPOS in $\mathrm{Y}$. Therefore $\mathrm{f}(\operatorname{spcl}(\mathrm{B})) \subseteq \mathrm{f}(\mathrm{cl}(\mathrm{B}))=\operatorname{spint}(\mathrm{f}(\mathrm{cl}(\mathrm{B})))$.

Sufficiency: Let $\mathrm{B} \subseteq \mathrm{X}$ be an IFCS. Then $\operatorname{cl}(\mathrm{B})=\mathrm{B}$. By hypothesis, $\mathrm{f}(\operatorname{spcl}(\mathrm{B})) \subseteq \operatorname{spint}(\mathrm{f}(\mathrm{cl}(\mathrm{B})))=\operatorname{spint}(\mathrm{f}(\mathrm{B}))$. But $\operatorname{spcl}(\mathrm{B})=\mathrm{B}$. Therefore $\mathrm{f}(\mathrm{B})=\mathrm{f}(\operatorname{spcl}(\mathrm{B})) \subseteq \operatorname{spint}(\mathrm{f}(\mathrm{B}) \subseteq \mathrm{f}(\mathrm{B})$. This implies $\mathrm{f}(\mathrm{B})$ is an IFSPOS in $\mathrm{Y}$ and hence an IFSPGOS in $\mathrm{Y}$. Hence $\mathrm{f}$ is an IFCSPGOM.

Theorem 5.10: An IFOM $\mathrm{f}:(\mathrm{X}, \tau) \rightarrow(\mathrm{Y}, \sigma)$ is an IFCSPGOM if IFSPGO(Y) = IFSPGC(Y).

Proof: Let $A \subseteq X$ be an IFOS. By hypothesis, $\mathrm{f}(\mathrm{A})$ is an IFOS in $\mathrm{Y}$ and hence is an IFSPGOS in $\mathrm{Y}$. Thus $\mathrm{f}(\mathrm{A})$ is an IFSPGCS in $\mathrm{Y}$, since IFSPGO(Y) $=$ IFSPGC(Y). Therefore $\mathrm{f}$ is an IFCSPGOM.

Definition 5.11: A mapping $\mathrm{f}:(\mathrm{X}, \tau) \rightarrow(\mathrm{Y}, \sigma)$ is said to be an intuitionistic fuzzy almost contra semipre generalized open mapping (IFaCSPGOM for short) if $\mathrm{f}(\mathrm{A})$ is an IFSPGCS in $\mathrm{Y}$ for every IFROS A in $\mathrm{X}$.

Theorem 5.12: Every IFCSPGOM is an IFaCSPGOM but not conversely.

Proof: Assume that $\mathrm{f}:(\mathrm{X}, \tau) \rightarrow(\mathrm{Y}, \sigma)$ be an IFCSPGOM. Let $A \subseteq X$ be an IFROS. Then $A$ is an IFOS in $X$. By hypothesis, $\mathrm{f}(\mathrm{A})$ is an IFSPGCS in Y. Hence $\mathrm{f}$ is an IFaCSPGOM.

Example 5.13: Let $X=\{a, b\}, Y=\{u, v\}, G_{1}=\langle x,(0.5,0.7)$, $(0.5,0.3)\rangle, \mathrm{G}_{2}=\langle\mathrm{x},(0.4,0.2),(0.5,0.4)\rangle$ and $\mathrm{G}_{3}=\langle\mathrm{x},(0.5$, $0.6),(0.5,0.4)\rangle$ and $\mathrm{G}_{4}=\langle\mathrm{y},(0.5,0.6),(0.5,0.4)\rangle$. Then $\tau=$ $\left\{0_{\sim}, \mathrm{G}_{1}, \mathrm{G}_{2}, \mathrm{G}_{3}, 1_{\sim}\right\}$ and $\sigma=\left\{0_{\sim}, \mathrm{G}_{4}, 1_{\sim}\right\}$ are IFTs on $\mathrm{X}$ and $\mathrm{Y}$ respectively. Define a mapping $\mathrm{f}:(\mathrm{X}, \tau) \rightarrow(\mathrm{Y}, \sigma)$ by $\mathrm{f}(\mathrm{a})=\mathrm{u}$ and $f(b)=v$. Then $f$ is an IFaCSPGOM but not an IFCSPGOM.

Theorem 5.14: If $\mathrm{f}:(\mathrm{X}, \tau) \rightarrow(\mathrm{Y}, \sigma)$ is a bijective mapping, where $\mathrm{Y}$ is an $\operatorname{IFSPT}_{1 / 2}$ space, then the following conditions are equivalent:

(i) $\mathrm{f}$ is an IFaCSPGOM

(ii) $\quad \mathrm{f}(\mathrm{A}) \in \operatorname{IFGSPO}(\mathrm{Y})$ for every $\mathrm{A} \in \operatorname{IFRC}(\mathrm{X})$

(iii) $\quad \mathrm{f}(\operatorname{int}(\mathrm{cl}(\mathrm{A}))) \in \mathrm{IFSPGC}(\mathrm{Y})$ for every IFOS $\mathrm{A} \subseteq \mathrm{X}$

(iv) $\quad \mathrm{f}(\operatorname{cl}(\operatorname{int}(\mathrm{A}))) \in \mathrm{IFSPGO}(\mathrm{Y})$ for every IFCS $\mathrm{A} \subseteq \mathrm{X}$

Proof: (i) $\Leftrightarrow$ (ii) is obvious.

(i) $\Rightarrow$ (iii) Let $A$ be any IFOS in $X$. Then $\operatorname{int}(\operatorname{cl}(A))$ is an IFROS in X. By hypothesis, $\mathrm{f}(\operatorname{int}(\mathrm{cl}(\mathrm{A})))$ is an IFSPGCS in $\mathrm{Y}$. Hence $\mathrm{f}(\operatorname{int}(\mathrm{cl}(\mathrm{A}))) \in \operatorname{IFSPGC}(\mathrm{Y})$.

(iii) $\Rightarrow$ (i) Let $A$ be any IFROS in X. Then A is an IFOS in X. By hypothesis, $\mathrm{f}(\operatorname{int}(\mathrm{cl}(\mathrm{A}))) \in \operatorname{IFSPGC}(\mathrm{Y})$. That is $\mathrm{f}(\mathrm{A}) \in$ IFSPGC(Y), since int(cl(A)) $=$ A. Hence $\mathrm{f}$ is an IFaCSPGOM. (ii) $\Leftrightarrow$ (iv) is similar as (i) $\Leftrightarrow$ (iii).

Definition 5.15: A mapping $\mathrm{f}:(\mathrm{X}, \tau) \rightarrow(\mathrm{Y}, \sigma)$ is said to be an intuitionistic fuzzy contra Msemipre generalized open mapping (IFCMSPGOM) if $\mathrm{f}(\mathrm{A})$ is an IFSPGCS in $\mathrm{Y}$ for every IFSPGOS A in X.
Example 5.16: Let $X=\{a, b\}, Y=\{u, v\}$ and $G_{1}=\langle x,(0.5$, $0.6),(0.5,0.4)\rangle, \mathrm{G}_{2}=\langle\mathrm{y},(0.2,0.3),(0.8,0.7)\rangle$. Then $\tau=\{0$, $\left.\mathrm{G}_{1,}, 1_{\sim}\right\}$ and $\sigma=\left\{0 \sim \mathrm{G}_{2}, 1 \sim\right\}$ are IFTs on $\mathrm{X}$ and $\mathrm{Y}$ respectively. Define a mapping $\mathrm{f}:(\mathrm{X}, \tau) \rightarrow(\mathrm{Y}, \sigma)$ by $\mathrm{f}(\mathrm{a})=\mathrm{u}$ and $\mathrm{f}(\mathrm{b})=\mathrm{v}$. Then $\mathrm{f}$ is an IFCMSPGOM.

Theorem 5.17: Let $\mathrm{f}:(\mathrm{X}, \tau) \rightarrow(\mathrm{Y}, \sigma)$ be a bijective mapping. Then the following statements are equivalent:

(i) $\mathrm{f}$ is an IFCMSPGOM,

(ii) $\quad \mathrm{f}(\mathrm{A})$ is an IFSPGOS in $\mathrm{Y}$ for every IFSPGCS $\mathrm{A}$ in X.

Proof: (i) $\Rightarrow$ (ii) Let A be an IFSPGCS in X. Then $A^{c}$ is an IFSPGOS in $\mathrm{X}$. By hypothesis, $\mathrm{f}\left(\mathrm{A}^{\mathrm{c}}\right)$ is an IFSPGCS in $\mathrm{Y}$. That is $\mathrm{f}(\mathrm{A})^{\mathrm{c}}$ is an IFSPGCS in $\mathrm{Y}$. Hence $\mathrm{f}(\mathrm{A})$ is an IFSPGOS in $\mathrm{Y}$.

(ii) $\Rightarrow$ (i) Let $A$ be an IFSPGOS in X. Then $A^{c}$ is an IFGSPCS in $X$. By hypothesis, $f\left(A^{c}\right)$ is an IFSPGOS in Y. Hence $f(A)$ is an IFSPGCS in $\mathrm{Y}$. Thus $\mathrm{f}$ is an IFCMSPGOM.

Theorem 5.18: Every IFCMSPGOM is an IFCSPGOM but not conversely.

Proof: Assume that $\mathrm{f}:(\mathrm{X}, \tau) \rightarrow(\mathrm{Y}, \sigma)$ be an IFCMSPGOM. Let $A \subseteq X$ be an IFOS. Then $A$ is an IFSPGOS in $X$. By hypothesis, $\mathrm{f}(\mathrm{A})$ is an IFSPGCS in $\mathrm{Y}$. Hence $\mathrm{f}$ is an IFCSPGOM.

Example 5.19: Let $X=\{a, b\}, Y=\{u, v\}$ and $G_{1}=\langle x,(0.5$, $0.4),(0.5,0.6)\rangle, \mathrm{G}_{2}=\langle\mathrm{y},(0.6,0.7),(0.4,0.3)\rangle$ and $\mathrm{G}_{3}=\langle\mathrm{y}$, $(0.4,0.7),(0.6,0.3)\rangle$. Then $\tau=\left\{0_{\sim}, \mathrm{G}_{1}, 1_{\sim}\right\}$ and $\sigma=\left\{0_{\sim}, \mathrm{G}_{2}, \mathrm{G}_{3}\right.$, $1 \sim\}$ are IFTs on $\mathrm{X}$ and $\mathrm{Y}$ respectively. Define a mappingf : (X, $\tau) \rightarrow(\mathrm{Y}, \sigma)$ by $\mathrm{f}(\mathrm{a})=\mathrm{u}$ and $\mathrm{f}(\mathrm{b})=\mathrm{v}$. Then $\mathrm{f}$ is an IFCSPGO mapping but not an IFCMSPGOM.

Theorem 5.20: Every IFCMSPGOM is an IFaCSPGO mapping but not conversely.

Proof: Assume that $\mathrm{f}: \mathrm{X} \rightarrow \mathrm{Y}$ be an IFCMSPGOM. Let $\mathrm{A} \subseteq \mathrm{X}$ be an IFROS. Then A is an IFSPGOS in X. By hypothesis, $\mathrm{f}(\mathrm{A})$ is an IFSPGCS in Y. Hence $\mathrm{f}$ is an IFaCSPGOM.

Example 5.21: Let $\mathrm{X}=\{\mathrm{a}, \mathrm{b}\}, \mathrm{Y}=\{\mathrm{u}, \mathrm{v}\}$ and $\mathrm{G}_{1}=\langle\mathrm{x},(0.5$, $0.4),(0.5,0.6)\rangle, \mathrm{G}_{2}=\langle\mathrm{y},(0.6,0.7),(0.4,0.3)\rangle$ and $\mathrm{G}_{3}=\langle\mathrm{y}$, $(0.4,0.7),(0.6,0.3)\rangle$. Then $\tau=\left\{0_{\sim}, \mathrm{G}_{1}, 1_{\sim}\right\}$ and $\sigma=\left\{0_{\sim}, \mathrm{G}_{2}, \mathrm{G}_{3}\right.$, $\left.1_{\sim}\right\}$ are IFT on $X$ and $Y$ respectively. Define a mapping $f:(X$, $\tau) \rightarrow(\mathrm{Y}, \sigma)$ by $\mathrm{f}(\mathrm{a})=\mathrm{u}$ and $\mathrm{f}(\mathrm{b})=\mathrm{v}$. Then $\mathrm{f}$ is an IFaCSPGO mapping but not an IFCMSPGO mapping

The relation between various types of intuitionistic fuzzy contra open maps is given in the following diagram.

\section{IFCSPGOmapIFaCSPGOmp}

\section{IFCMSPGO map}

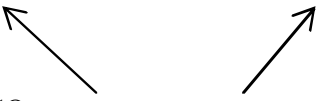

The reverse implications are not true in general in the above diagram.

Theorem 5.22: (i) If $\mathrm{f}:(\mathrm{X}, \tau) \rightarrow(\mathrm{Y}, \sigma)$ is an IFOM and $\mathrm{g}$ : $(\mathrm{Y}, \sigma) \rightarrow(\mathrm{Z}, \eta)$ be an IFCSPGOM, then $\mathrm{g}$ of is an IFCSPGOM

(ii) If $\mathrm{f}:(\mathrm{X}, \tau) \rightarrow(\mathrm{Y}, \sigma)$ is an IFCSPGOM and $\mathrm{g}:(\mathrm{Y}, \sigma) \rightarrow$ $(\mathrm{Z}, \eta)$ is an IFMSPGCM, then $\mathrm{g}$ of is an IFCSPGOM.

(iii) If $\mathrm{f}:(\mathrm{X}, \tau) \rightarrow(\mathrm{Y}, \sigma)$ is an IFSPGOM and $\mathrm{g}:(\mathrm{Y}, \sigma) \rightarrow(\mathrm{Z}$, $\eta$ )is an IFCMSPGOM, then $\mathrm{g}$ of is an IFCSPGOM. 
(iv) If $\mathrm{f}:(\mathrm{X}, \tau) \rightarrow(\mathrm{Y}, \sigma)$ is an IFCSPGOM and $\mathrm{g}:(\mathrm{Y}, \sigma) \rightarrow$ $(Z, \eta)$ is an IFCMSPGOM, then $\mathrm{g}$ o $\mathrm{f}:(\mathrm{X}, \tau) \rightarrow(\mathrm{Z}, \eta)$ is an IFSPGOM.

Proof: (i) Let A be an IFOS in X. Then $\mathrm{f}(\mathrm{A})$ is an IFOS in Y. Therefore $g(f(A))$ is an IFSPGCS in Z. Hence $g$ of is an IFCSPGOM.

(ii) Let $\mathrm{A}$ be an IFOS in $\mathrm{X}$. Then $\mathrm{f}(\mathrm{A})$ is an IFSPGCS in $\mathrm{Y}$. Therefore $\mathrm{g}(\mathrm{f}(\mathrm{A}))$ is an IFSPGCS in $\mathrm{Z}$. Hence $\mathrm{g}$ of is an IFCSPGOM.

(iii) Let $A$ be an IFOS in X. Then $\mathrm{f}(\mathrm{A})$ is an IFSPGOS in $\mathrm{Y}$. Therefore $\mathrm{g}(\mathrm{f}(\mathrm{A}))$ is an IFSPGCS in $\mathrm{Z}$. Hence $\mathrm{g}$ of is an IFCSPGOM.

(iv) Let $A$ be an IFOS in X. Then $\mathrm{f}(\mathrm{A})$ is an IFSPGCS in Y, since $\mathrm{f}$ is an IFCSPGOM. Since $\mathrm{g}$ is an IFCMSPGOM, $\mathrm{g}(\mathrm{f}(\mathrm{A})$ ) is an IFSPGOS in Z. Therefore $g$ of is an IFSPGOM.

Theorem 5.23: If $\mathrm{f}:(\mathrm{X}, \tau) \rightarrow(\mathrm{Y}, \sigma)$ is an IFCMSPGOM, then for any IFSPGCS A in X and for any IFP $p_{(\alpha, \beta)} \in \mathrm{Y}$, if $\mathrm{f}^{-}$ ${ }^{1}\left(\mathrm{p}_{(\alpha, \beta)}\right)_{q} \mathrm{~A}$, then $\mathrm{p}_{(\alpha, \beta) q} \operatorname{spgint}(\mathrm{f}(\mathrm{A}))$.

Proof: Let $A \subseteq X$ be an IFSPGCSand let $p_{(\alpha, \beta)} \in Y$. Assume that $\mathrm{f}^{-1}\left(\mathrm{p}_{(\alpha, \beta)}\right)_{\mathrm{q}} \mathrm{A}$. Thenp $\mathrm{p}_{(\alpha, \beta) \mathrm{q}} \mathrm{f}(\mathrm{A})$. By hypothesis, $\mathrm{f}(\mathrm{A})$ is an IFSPGOS in $Y$. This implies spgint $(f(A))=f(A)$. Hence $p_{(\alpha, \beta)}$ ${ }_{q} \operatorname{spgint}(f(A))$.

\section{REFERENCES}

[1] K. Atanassov, Intuitionistic fuzzy sets, Fuzzy Sets and Systems, 20, 1986, 87-96.

[2] C. L. Chang, Fuzzy topological spaces, J.Math.Anal.Appl. 24, 1968, 182-190.

[3] D. Coker, An introduction to intuitionistic fuzzy topological space, Fuzzy Sets and Systems, 88, 1997, 81-89.

[4] E.Ekici and B.Krsteska, Intuitionistic fuzzy contra strong pre-continuity, Facta Univ. Ser.Math. Inform., 2007, 273-284.

[5] H. Gurcay, Es. A. Haydar and D. Coker, On fuzzy continuity in intuitionistic fuzzy topological spaces, J.Fuzzy Math.5 (2) , 1997, 365-378.

[6] Seok Jong Lee and EunPyo Lee, The category of intuitionistic fuzzy topological spaces, Bull. Korean Math. Soc. 37, No. 1, 2000, pp. 63-76.

[7] M. Thirumalaiswamy and K. M. Arifmohammed, Semipre Generalized Open Sets and Applications of Semipre Generalized Closed Sets in Intuitionistic Fuzzy Topological Spaces (submitted).

[8] M. Thirumalaiswamy and K. M. Arifmohammed, Semipre Generalized Closed Mappings in Intuitionistic Fuzzy Topological Spaces (submitted).

[9] M. Thirumalaiswamy and K. Ramesh, Intuitionistic fuzzy Semipre Generalized Closed Sets (submitted).

[10] M. Thirumalaiswamy and K. Ramesh, Semipre Generalized Continuous and Irresolute Mappings in Intuitionistic Fuzzy Topological Space (submitted).

[11] M. Thirumalaiswamy and K. Ramesh, Semipre Generalized Homeomorphisms in Intuitionistic Fuzzy Topological Spaces (submitted)
[12] Young Bae Jun and Seok- Zun Song, Intuitionistic fuzzy semi-pre open sets and Intuitionistic fuzzy semi-pre continuous mappings, Jour. of Appl. Math \& computing, 2005, 467-474.

[13] L. A. Zadeh, Fuzzy sets, Information and control, 8, 1965, 338-353. 